\title{
Electron Beam Lithography for Fine Dot Arrays with Nanometer-Sized Dot and Pitch
}

\author{
Sumio Hosaka \\ Gunma University \\ Japan
}

\section{Introduction}

Recently, electron beam (EB) lithography has been applied to mask and reticle pattern draw, for fabricating semiconductor devices, and nanometer-sized pattern direct writing for developing of new concept nano-device. Mainly, the developing of practical EB drawing system has been started since 1960s, and fine pattern formation has also been studied together with the system development [1-3]. Regarding EB-drawn pattern size, at first, micron and submicron-sized pattern has been drawn on mask blank and directly on the device [4]. Today, the pattern size miniaturizes to nanometer-size of less than $20 \mathrm{~nm}$ in research $[5,6]$.

Especially, I have focused the EB lithography into the possibility to form fine dot and fine pitched dot 2-dimensional arrays for patterned media and quantum devices. The research has been done by dependences of resist material and thickness on drawing of fine dot arrays with nanometer-sized pitch in EB drawing, theoretically and experimentally. I have used Monte Carlo simulation and a conventional EB drawing system combined with scanning electron microscope (SEM) and EB drawing controller [7].

In this chapter, I describe key factors such as resist type, resist thickness, proximity effect, etc for a formation of nanometer-pitch dot arrays, a limitation of the EB-drawn size theoretically and experimentally, and demonstrate the applications to dry-etching process and nano-imprinting.

\section{Monte Carlo simulation of electron scattering in solid for EB lithography} [8]

Electron scattering in the resist and substrate is described based on its scattering angle, mean free path, energy loss, etc. Trajectories of incident electrons and energy deposition distributions (EDDs) in the resist are calculated. From the EDD, EB drawn resist dot profiles are estimated. The formation of nanometer sized pattern for electron energy, resist thickness and resist type can be studied. The EDD in $100 \mathrm{~nm}$-thick resist on Si substrate were calculated for small pattern drawing. The calculations show that $4 \mathrm{~nm}$-wide pattern will be formed when resist thickness is less than $30 \mathrm{~nm}$. Furthermore, a negative resist is more suitable than positive resist by the estimation of a shape of the EDD.

\subsection{Calculation model for Monte Carlo simulation of electron scattering}

For the treatment of electron elastic scattering, the screened Rutherford scattering model [11] is employed as follow, 


$$
\frac{d \sigma_{i}}{d \Omega}=\frac{e^{4} Z_{i}\left(Z_{i}+1\right)}{4 E^{2}(1-\cos \theta+2 \beta)}
$$

where the $\beta$ is the screening parameter which is given by

$$
\beta=\frac{1}{4}\left(\frac{1.12 \lambda_{0} h}{2 \pi p}\right), \lambda_{0}=Z^{1 / 3} / 0.885 a_{0}
$$

where the e is electronic charge, th the $\theta$ is scattering angle, the $a_{0}$ is Bohr radius, the $h$ is Planck's constant and the $p$ is the electron momentum. Step length is calculated based on the electron mean free path $\Lambda$. The $\Lambda$ is given by

$$
\Lambda=\frac{1}{n \sigma}=\frac{A}{N \rho \sigma}
$$

where the $\mathrm{n}$ is volume density of atoms, the $\sigma$ is total cross section calculated from differential scattering cross section, the $\mathrm{N}$ is Avogadro's number, the $\mathrm{A}$ is atomic weight and the $\rho$ is mass density. Scattering angle $\theta$ and azimuthal angle $\phi$ can be obtained using the following equations:

$$
\theta=\cos ^{-1}\left(1-\frac{2 \beta R_{1}}{1-\beta-R_{1}}\right), \phi=2 \pi R_{2}
$$

where the $R_{1}$ and $R_{2}$ are independent equidistributed random number between 0 and 1 . Since the electron suffers scattering along its trajectory, it continuously loses its kinetic energy along its trajectory. In Monte Carlo simulation, incident electron is slowing down following Bethe's formula, which is a good empirical method of calculating this energy loss in electron solid interaction. The Bethe's approximation is given by

$$
-\frac{d E}{d s}=\frac{2 \pi e^{4}}{E} \sum_{i} n_{i} Z_{i} \ln \left(\frac{1.166 E}{J_{i}}\right)
$$

where the $n_{i}$ is volume density of atoms, the $J_{i}$ is mean ionization energy of atom $\mathrm{i}$. The terminal energy of the $\mathrm{n}^{\text {th }}$ scattering is:

$$
E_{n+1}=E_{n}-|d E / d s|_{E_{n}} \cdot \Lambda_{n}
$$

where the $E_{n}$ is the energy of the (n-1)th scattering, the $\Lambda_{n}$ is step length, and the $|d E / d s|_{E_{n}}$ is the energy loss rate which can be obtained from Eq. (2.5).

The EDD is an important parameter in consideration of EBL. In order to calculate the EDD in resist, we use cylindrical coordination system. We divide the resist layer along Z-axis into several thin sub-layers. The EDD was calculated in a radius-depth coordination system. This means that the resist layer was devided into many small concentric rings. The simulation was excuted to calculate the total energies $E(r, z)$ in every unit ring for EDD function. The ring volume $\Delta V$ is given by following equation,

$$
\Delta V=\left(\pi(r+\Delta r)^{2}-\pi r^{2}\right) \cdot \Delta Z
$$


where the $\Delta \mathrm{Z}$ is the thickness of sub-layer and the $\Delta r$ is increment in radius direction, From the volume, the EDD function is given by following equation,

$$
E D D(r, z)=E(r, z) /\left(\Delta V \cdot N_{0}\right)
$$

where the $N_{0}$ is total number of incident electron.

\subsection{Simulation results and discussion}

\subsubsection{Description and electron trajectories}

Monte Carlo simulation has been excuted in energetic electrons impinging in thin film of Si covered with resist material. By using uniform random numbers between 0 and 1, the scattering angles $\theta$ and $\phi$ can be calculated by using Eq. (2.4). Using Eqs. (2.5) and (2.6) ,we can calculate the energy loss $\Delta E$ due to scattering of the electrons with atoms in the sample along its trajectory. The trajectory of the electron was traced till its energy slowed down to $50 \mathrm{eV}$. PMMA $\left(\mathrm{C}_{5} \mathrm{H}_{8} \mathrm{O}_{2}\right)$ with a compound of carbon $(\mathrm{C})$, hydrogen $(\mathrm{H})$ and oxygen $(\mathrm{O})$ was used as the typical resist. In the simulation, we use random sampling method to determine the scattering center, the step length and use a new coordinate conversion method [12] for calculating the trajectories of electrons. The initial energies of the incident electrons are taken to be $30 \mathrm{keV}$ and $10 \mathrm{keV}$. The scattering trajectories of electrons with different incident beam energies in the resist material was used with the same as PMMA resist layer on Si target are shown in Figs. 2. 1- 2. 4. In the simulation, the thickness of the resist layer of $100 \mathrm{~nm}$ and the number of incident electrons of 500 was used. With incident energy of $30 \mathrm{keV}$, the penetration depth was about $3.5 \mu \mathrm{m}$ and lateral range was about $1.5 \mu \mathrm{m}$ in $\mathrm{Si}$ (Fig. 2. 1). In the resist layer, the electron scattering was expanded only to about $20 \mathrm{~nm}$ in radius direction (Fig. 2. 2). Although using $10 \mathrm{keV}$ incident electrons can diffuse as deep as $0.5 \mu \mathrm{m}$ into the sample (Fig. 2. 3) but lateral range was about $50 \mathrm{~nm}$ in the resist layer which is larger than that of $30 \mathrm{keV}$ (Fig. 2. 4). It indicated that as the energy decreases, the electrons scattering lateral range is expanded in the thin resist layer at the top.

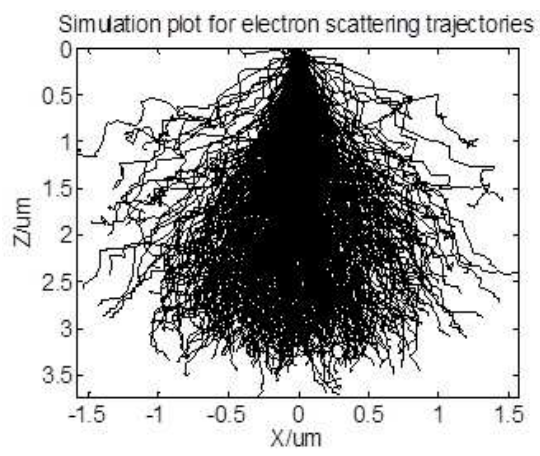

Fig. 2.1. Electron scattering trajectories at incident energy $30 \mathrm{keV}$ 


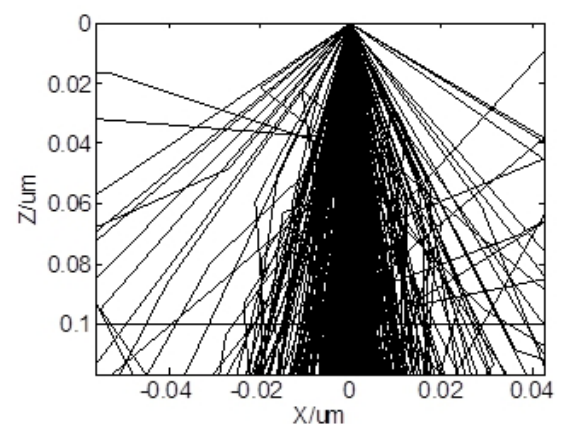

Fig. 2.2. Trajectories in resist $(100 \mathrm{~nm})$ at incident energy $30 \mathrm{keV}$.

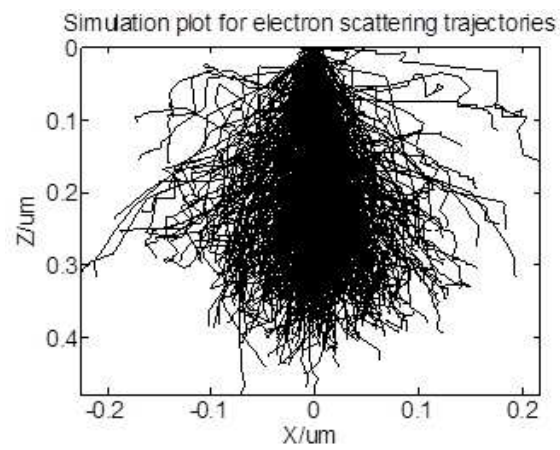

Fig. 2.3. Electron scattering trajectories at incident energy $10 \mathrm{keV}$.

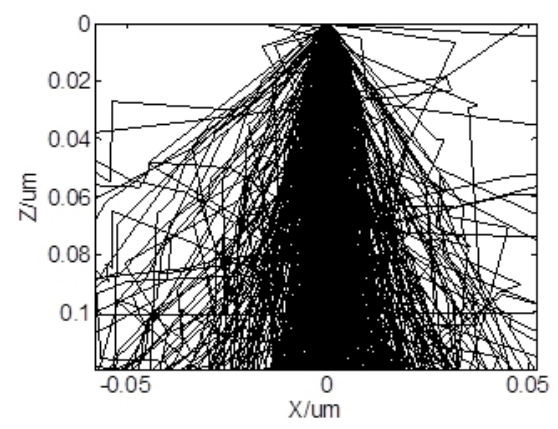

Fig. 2.4. Trajectories in resist $(100 \mathrm{~nm})$ at incident energy $10 \mathrm{keV}$.

\subsubsection{Energy deposition distribution (EDD)}

The energy deposition density at various positions in depths and radius in the thin resist was calculated. The thickness of the resist was $100 \mathrm{~nm}$, and the incident energy was $30 \mathrm{keV}$. The $\Delta Z$ and $\Delta r$ were $2 \mathrm{~nm}$, and the number of electrons was 30000. Fig. 2.5 shows the EDD 
in the resist layer of various depths $10 \mathrm{~nm}, 50 \mathrm{~nm}$ and $100 \mathrm{~nm}$. It can be clearly seen that the shallower the depth from the surface of the resist, the narrower and the shaper the EDD. Fig. 2.6 shows the relationship between resist depth and standard deviation $\sigma$ of the EDD assuming that the EDD is approximated by Gauss distribution.

$$
\operatorname{EDD}(r)=\frac{1}{\sqrt{2 \pi}} \cdot \frac{1}{\sigma} \exp \left(-\frac{\left(r-r_{0}\right)^{2}}{2 \sigma^{2}}\right)
$$

It indicates that small pattern could be produced by using thin resist. It can effectively reduce proximity effects and thus greatly improve resolution.

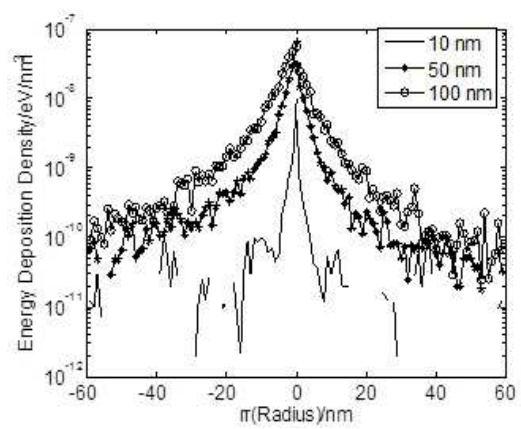

Fig. 2.5. Energy deposition distribution of different depth of resist.

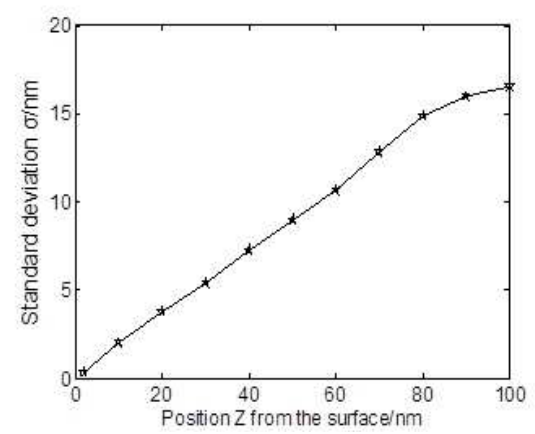

Fig. 2.6. The relationship between resist depth and width of dot.

\subsubsection{Consideration for resist development based on EDD}

Resist development is assumed as the resist molecule are solved and linked over the critical energy density so that they are soluble and insoluble in positive and negative resists, respectively. Figs. 2. 7(a)-(d) show the area over the critical energy density of $28.125 \mathrm{keV} / \mathrm{cm}^{3}-0.5 \mathrm{keV} / \mathrm{cm}^{3}$. It is clear that small pattern formation is possible by selecting large critical energy density, which corresponds to small exposure dosage in experiment. In the positive resist, however, it is very important to solve the top layer at 
first. The energy densities of the top layer do not reach to the critical energy density in Figs. 2. 7(a)-(c). As the result, no patterning occurs in the energy region as shown in Figs. 2. 7(e)-(g). When the critical energy density is less than $0.5 \mathrm{keV} / \mathrm{cm}^{3}$, the hole pattern appears as Fig. 2. 7(h). The hole diameter increases with the depth in the resist layer. In our experiment, however, the small diameter of about $4 \mathrm{~nm}$ disappears. This may be caused by capillary force. The minimum diameter of about $7 \mathrm{~nm}$ was obtained in previous experiment using ZEP520 positive resist [7]. On the other hand, Figs. 2. 7(i)-(l) show the developed resist profiles at various critical energy densities. As the linked molecule is remained on the substrate based on negative resist development mechanism, nanometersized patterns are formed as shown in Fig. 2.7(i), although the height of the resist pattern is not complete and short. It is clear that the smaller pattern size is obtained by selecting the heigher critical energy density,but the hight of the resist pattern decreases as the critical energy density increases. Therefore, negative resist is very suitable to form nanometer-sized pattern.
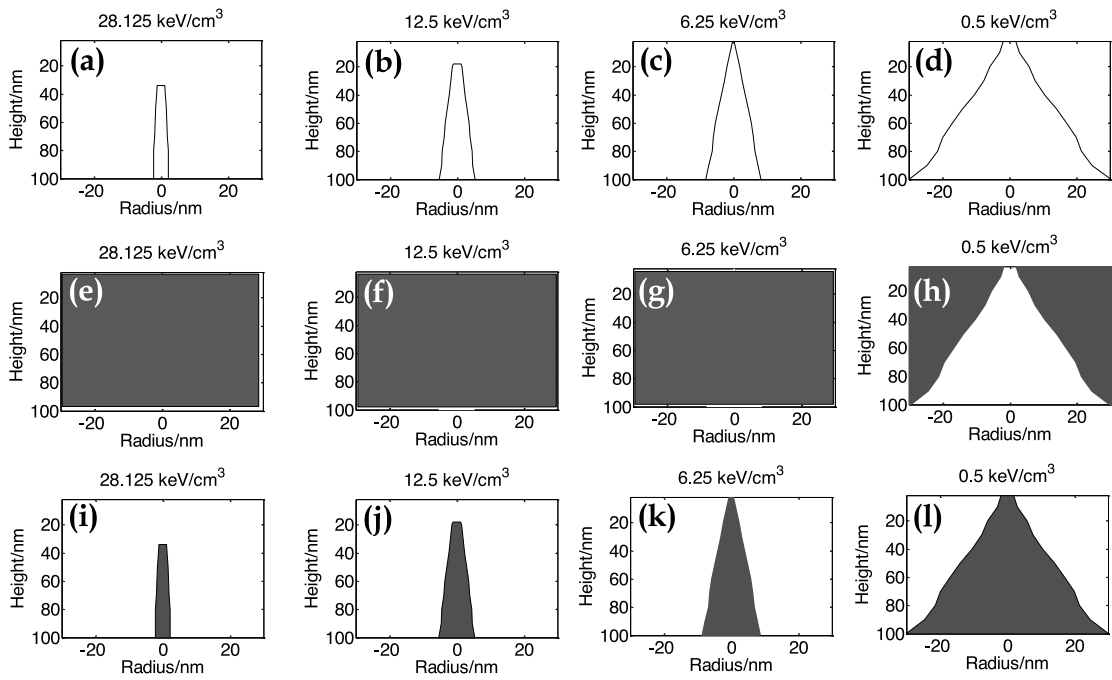

Fig. 2.7. Simulated resist profiles at various critical energies; (a) resist region over 28.125 $\mathrm{keV} / \mathrm{cm}^{2}$, (b) $12.5 \mathrm{keV} / \mathrm{cm}^{2}$, (c) $6.25 \mathrm{keV} / \mathrm{cm}^{2}$, (d) $0.5 \mathrm{keV} / \mathrm{cm}^{2}$, (e)-(h) positive resist region remained by development, (i)-(l) remained negative resist regions.

\section{Formation of highly packed fine pit and dot arrays using EB drawing with positive and negative resists $[7,13]$}

Fine bit arrays formation for an ultrahigh density optical and magnetic recordings has experimentally been studied using EB drawing with a high resolution scanning electron microscope (HR-SEM), a drawing controller [7] and positive and negative EB resists. As experimental results, calixarene negative EB resist is very suitable to form an ultrahigh packed resist dot arrays pattern, comparing with ZEP520 positive resist as same as described in previous section. We obtained very fine dot arrays with a diameter of $<15 \mathrm{~nm}$, and 2-dimensional pitch of $<30 \mathrm{~nm}$. 


\subsection{EB-drawing system [7]}

I have already reported key technologies which enable ultrahigh packing over $1 \mathrm{~Tb} / \mathrm{in}^{2}$ : (1) the use of an EB drawing system with a fine probe and large probe current, (2) the thinning of the resist to prevent the spread of incident electron scattering in the resist, and (3) the design of a highly packed pattern with a hexagonal or centered rectangular lattice structure to avoid the proximity effect (Fig. 3. 1). The EB drawing system consists of a HR-SEM (JSM6500F, JEOL, Ltd.) and a writing controller (Tokyo Technology Co., Ltd.) (Fig. 3. 2). The drawing was done on a resist coating on a piece of Si placed on the $X Y$ table, which was not moved during the EB writing. This type system is very suitable for checking the limit of the drawing pattern size, because the stage position error can be neglected. The system provides a high probe current of $2 \mathrm{nA}$ at a resolution of $2 \mathrm{~nm}$. We used the system under a probe current of $100 \mathrm{pA}$ and an acceleration voltage of $30 \mathrm{kV}$. In the drawing, the address resolutions were $10 \mathrm{~nm}$ and $2.5 \mathrm{~nm}$ for ZEP520 and calixarene [14, 15] resists, respectively. Development was carried out using the commercial developers ZED-N50 (MIBK+IPA) and ZEP-RD (xylene) for $210 \mathrm{sec}$ and $180 \mathrm{sec}$ for ZEP520 and calixarene, respectively. In particular, we adjusted the focus to get the fine probe on the sample surface at a magnification of $250 \mathrm{k}-200 \mathrm{k}$.

In order to achieve 1-Tb/in ${ }^{2}$ storage patterned media, we carried out experiments to confirm whether EB writing can form very fine pit or dot arrays with a pitch of $<60 \mathrm{~nm}$ or not. At first, we coated the resist on a piece of $S i$ substrate with a thickness of $70 \mathrm{~nm}$ and $15 \mathrm{~nm}$ in ZEP520 and calixarene, respectively. After pre-baking, we drew ultrahigh-packed pit and dot patterns with a pitch of 20-60 nm. After developing and rinsing the resists, we checked the drawn patterns using the same HR-SEM. Thinning allows not only to prevent electron scattering extension in the resist, but also to avoid electron charging. We determined the minimum thickness at which there is sufficient contrast and no damage to the resist during SEM observation. The thickness of $70 \mathrm{~nm}$ in ZEP520 resist was decided by electron damage and contrast signal in SEM. I could not obtain the high magnitude SEM image in a thickness range of less than $70 \mathrm{~nm}$.

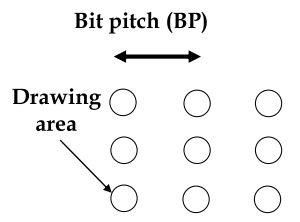

(a)

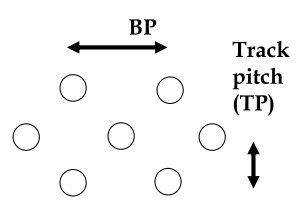

(b)

Fig. 3.1. Bit arrangement for highly packed bits array; (a) rectangular lattice pattern and (b) centered rectangular lattice pattern used here.

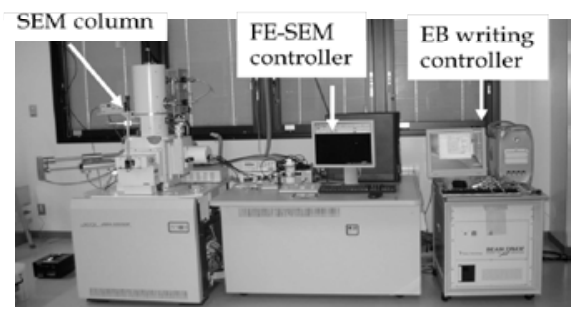

Fig. 3.2. Overview image of conventional EB drawing system. 


\subsection{EB drawing $[7,13]$}

\subsubsection{Using ZEP520 positive EB resist}

Figure 3.3 shows SEM images of ZEP520 pit patterns drawn at an exposure dosage of around $180 \mu \mathrm{C} / \mathrm{cm}^{2}$. The figure shows that the minimum pit arrays were drawn with a minimum pit diameter of $<20 \mathrm{~nm}$ at a pitch of $40 \mathrm{~nm} \times 60 \mathrm{~nm}$ [13]. We could not form higherpacked pit patterns than this. Furthermore, the pit size drastically changed, with a fluctuation of about 18 $\mathrm{nm}$ in this pitch arrays pattern and about $11 \mathrm{~nm}$ in the case of a pitch of $100 \mathrm{~nm} \times 60 \mathrm{~nm}$ (Fig. 3 . 4). This indicates that the pit array pattern with a pitch of $40 \mathrm{~nm} \times 60 \mathrm{~nm}$ is the limit for ZEP520. This pattern corresponds to about $270 \mathrm{~Gb} / \mathrm{in}^{2}$. But it is not practically usable because the fluctuations are too large. In addition, the minimum pit diameter is about $7 \mathrm{~nm}$ in Fig. 3. 3 . Comparing with Monte Carlo Simulation result, the pit diameter is larger than simulated size of $4 \mathrm{~nm}$. This is caused by capillary force between pit and developer.

$\mathrm{BP}: 60 \mathrm{~nm}$ and $\mathrm{TP}: 50 \mathrm{~nm}$

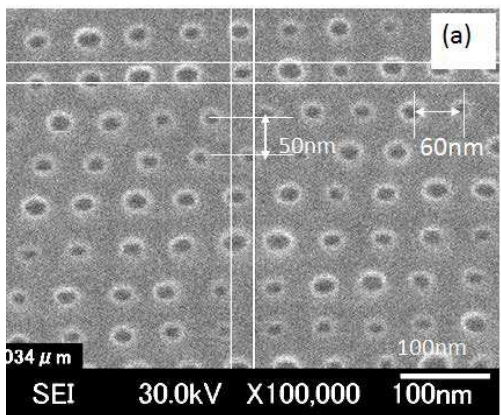

$\mathrm{BP}: 60 \mathrm{~nm}$ and $\mathrm{TP}: 40 \mathrm{~nm}$

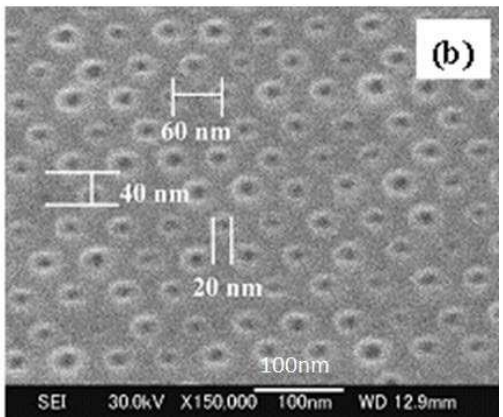

Fig. 3.3. SEM images of ultrahigh packed pit resist pattern using ZEP520 $\left(180 \mu \mathrm{C} / \mathrm{cm}^{2}, 30\right.$ $\mathrm{kV})$, (a) pitch of $60 \mathrm{~nm} \times$ of $50 \mathrm{~nm}$, (b) $60 \mathrm{~nm} \times 40 \mathrm{~nm}$.
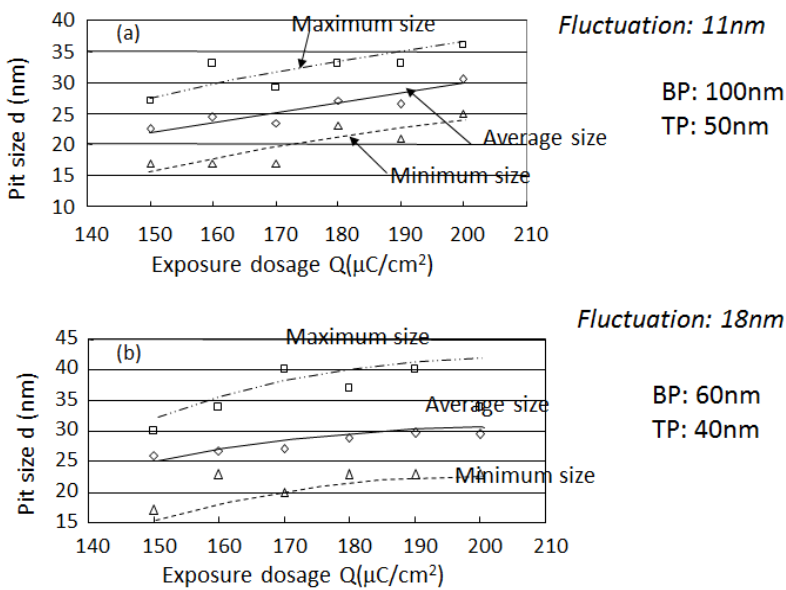

Fluctuation: $18 \mathrm{~nm}$

BP: $60 \mathrm{~nm}$

TP: $40 \mathrm{~nm}$

Fig. 3.4. Variations of ZEP520 resist pit width in ultrahigh packed pit arrays (a) with a pitch of $100 \mathrm{~nm} \times 50 \mathrm{~nm}$ and (b) $60 \mathrm{~nm} \times 40 \mathrm{~nm}$ for exposure dosage at $30 \mathrm{kV}$. 


\subsubsection{Using calixarene negative EB resist}

Figure 3.5 shows SEM images of ultrahigh-packed dot arrays resist patterns (a) at a pitch of $30 \mathrm{~nm} \times 30 \mathrm{~nm}$, and (b) $30 \mathrm{~nm} \times 25 \mathrm{~nm}$. The exposure dosage was $40 \mathrm{mC} / \mathrm{in}^{2}$. In these experiments, we succeeded in obtaining high packed dot arrays pattern (Fig. 3. 5(b)). The dot size was 11 to $14 \mathrm{~nm}$ in diameter. The size fluctuation was about 2 or $3 \mathrm{~nm}$ and almost constant in the range of 30 to $45 \mathrm{mC} / \mathrm{cm}^{2}$. This resist is very suitable to nano-fabrication (Fig. 3. 6).

Calixarene resist, however, has the drawback that its sensitivity is too low for mass production purposes. It takes much time to draw the dot arrays pattern over large sample. We have to develop a new resist with sensitivity higher by 2 orders of magnitude. The reason for its low sensitivity is in related with its molecule size. A lot of electrons are required to change the calixarene molecule to large molecular (weight: >several 10000s) for insolubility by linking many calixarene molecular (weight: about 600).

$30 \mathrm{~nm} \times 30 \mathrm{~nm}$

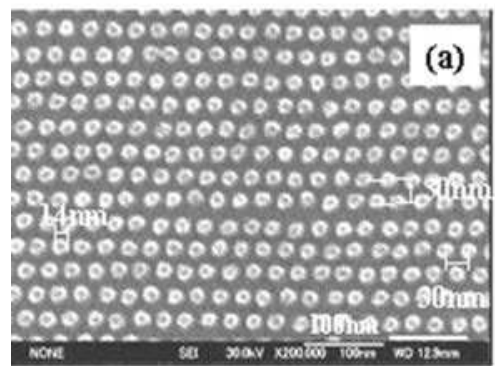

$30 \mathrm{~nm} \times 25 \mathrm{~nm}$

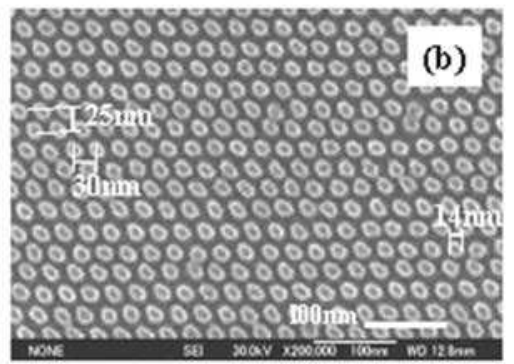

Fig. 3.5. SEM images of ultrahigh packed dot resist pattern using calixarene $\left(14 \mathrm{mC} / \mathrm{cm}^{2}\right.$, $30 \mathrm{kV})$, (a) pitch of $30 \mathrm{~nm} \times 30 \mathrm{~nm}$, (b) $30 \mathrm{~nm} \times 25 \mathrm{~nm}$.
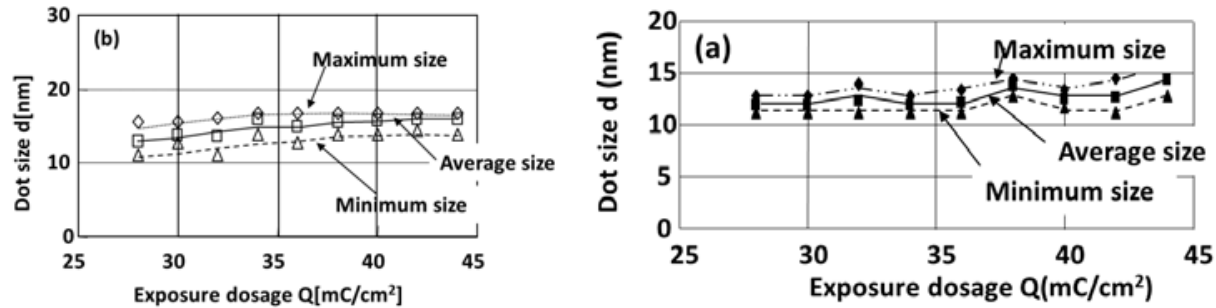

Fig. 3.6. Variations of the calixarene dot size in ultra-high-packed dot arrays; (a) pitch of 30 $\mathrm{nm} \times 30 \mathrm{~nm}$ and (b) $25 \mathrm{~nm} \times 25 \mathrm{~nm}$.

\subsection{Consideration of the different limitations in ZEP520 and calixarene}

The difference between the limitations has been investigated using the exposure intensity distribution (EID) and EDD in Monte Carlo simulation. The EID functions were determined by measuring the widths of one-line patterns drawn under various exposure dosages. We obtained the change of the required exposure dosage for the line-width, and then the EID from the change. 
The EID is defined by Eq. (3.1), assuming that the distribution is Gaussian. The $1^{\text {st }}$ and $2^{\text {nd }}$ terms in Eq. (3.1) represent the energy depositions due to electron forward scattering (FS) and backward scattering (BS), respectively.

$$
E(r)=C_{1} \exp \left(-\frac{r^{2}}{\sigma_{1}^{2}}\right)+C_{2} \exp \left(-\frac{r^{2}}{\sigma_{2}^{2}}\right)
$$

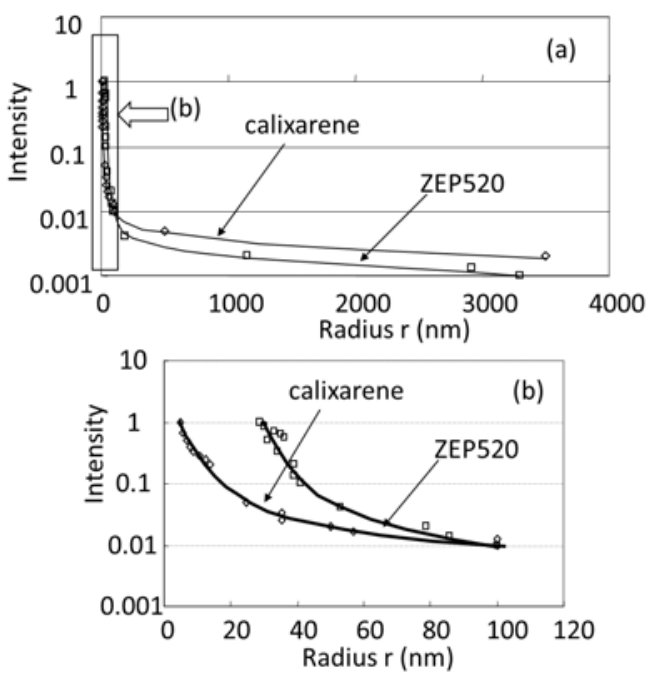

Fig. 3.7. EID functions measured by using ZEP520 and calixarene EB-drawing at $30 \mathrm{keV}$.

For the miniaturization of the bit size, the $\sigma_{1}$ value in the $1^{\text {st }}$ term is crucial. In the experiments, the exposure dosages were changed from $10 \mu \mathrm{C} / \mathrm{cm}^{2}$ to $5 \mathrm{C} / \mathrm{cm}^{2}$. Then, we obtained the EIDs using ZEP520 and calixarene, as shown in Fig. 3. 7. Figure 3. 7 shows the $1^{\text {st }}$ term in detail. When we roughly fit the EID function to Eq. (3.1), the $\sigma_{1}$ values were about $5 \mathrm{~nm}$ and $20 \mathrm{~nm}$ in calixarene and ZEP520, respectively. In the Monte Carlo simulation, the $\sigma_{1}$ values were about $2 \mathrm{~nm}$ and $3 \mathrm{~nm}$ at a resist thickness of $15 \mathrm{~nm}$ and 70 $\mathrm{nm}$, respectively (Fig. 4. 1). Although the values were calculated under the condition of 30-keV electron incidence on PMMA resist on a Si substrate and are slightly smaller than those using calixarene and ZEP520, we consider that they are roughly the same as those using PMMA because the resist thicknesses are very thin. When the electron probe size of $2 \mathrm{~nm}$ and the molecular size of 1 and $3 \mathrm{~nm}$ in calixarene and ZEP520, respectively, are considered, the experimental value becomes $13 \mathrm{~nm}$ larger than the estimated value in ZEP520, while the values are almost same in calixarene. This may be due to the molecular size, structure of the ZEP520 resist and capillary force in the development. The size of ZEP520 is a few nm assuming to be spherical. Sometimes, ZEP520 may be in a chain structure when the molecule is not solved after EB exposure. This comparison indicates that the smallest pattern in EB writing may be determined by the resist's molecular size, structure and resist type. 


\section{Challenge of formation of less than $20 \mathrm{~nm} \times 20 \mathrm{~nm}$ very fine pitch dot arrays using $30 \mathrm{keV}$ EB drawing with thin calixarene resists $[5,16,17]$}

The possibility to achieve very fine dot arrays with a pitch of less than $20 \mathrm{~nm} \times 20 \mathrm{~nm}$ using 30 $\mathrm{keV}$ EB drawing with calixarene resist has been investigated. In order to form such a pattern, the resist thickness dependence on dot size and packing has been studied. In this section, EB drawing with extremely thin film for very highly packed dot arrays formation is described. As the experimental results, it is demonstrated to form higher packed dot arrays pattern with a pitch of $20 \mathrm{~nm} \times 20 \mathrm{~nm}$ and $18 \mathrm{~nm} \times 18 \mathrm{~nm}$ in 13-nm-thick resist using $30 \mathrm{keV}$ electron beam.

\subsection{Electron scattering in thin resist film for fine dot arrays [16]}

In order to check the resist thickness dependence on formation of very fine pitch dot arrays using $30 \mathrm{keV}$ electrons, the EDD was calculated using Monte Carlo simulation. From the simulation, the possibility to achieve a very fine pitch dot arrays is studied. It is very important to study the EDD because the resist dot formation occurs by linking the molecula enhanced by the energy in a case of using negative resist. The EDD function is represented as Eq. (3. 1), assuming that the distribution consists of 2 Gaussian distributions as described in last section. At least, the miniaturization of the dot size, the $\sigma_{1}$ value in the first term is very crucial.

Figure 4. 1 shows the EDDs with PMMA resist thickness of $15 \mathrm{~nm}, 70 \mathrm{~nm}$ and $200 \mathrm{~nm}$ on Si substrate with $30 \mathrm{keV}$ electrons using Monte Carlo simulation. From the result, the $\sigma_{1}$ values are about $2 \mathrm{~nm}, 3 \mathrm{~nm}$ and $8 \mathrm{~nm}$ at a resist thickness of $15 \mathrm{~nm}, 70 \mathrm{~nm}$ and $200 \mathrm{~nm}$, respectively. Figure 4.2 shows a variation of the $\sigma_{1}$ value for the resist thicknesses. As the resist thickness decreases, the $\sigma_{1}$ value becomes small. We can estimate the $\sigma_{1}$ value of about $1.5 \mathrm{~nm}$ at a resist thickness of $10 \mathrm{~nm}$. This means that it is possible to form finer pitch dot arrays than that in previous section using such a thin film. Therefore, it is very important to use resist film as thin as possible for formation of very fine pitch dot arrays.

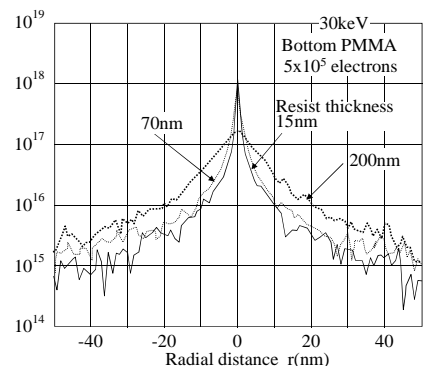

Fig. 4.1. Monte Carlo calculated result of energy deposition distributions (EDDs) for various resist thickness of PMMA on Si substrate.

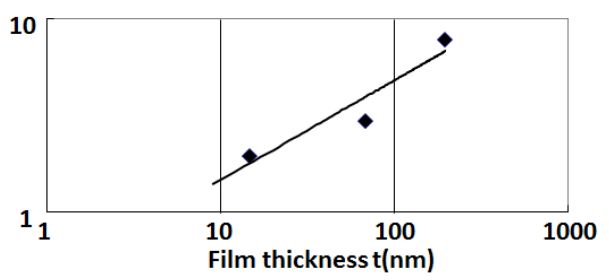

Fig. 4.2. A variation of the $\sigma_{1}$ value in EDD for the resist thicknesses. 


\subsection{EB drawing and sample preparation}

The conventional EB drawing system was used as described in section 3. 1. The drawing was done on a resist layer coating on a piece of $\mathrm{Si}$ after we set the sample on the XY table in the system. The EB drawing was done under a probe current of $100 \mathrm{pA}$ at an acceleration voltage of $30 \mathrm{kV}$. In the other system parameters, the address resolution was $2.5 \mathrm{~nm}$ in a drawing field of $25 \mu \mathrm{m} \times 25 \mu \mathrm{m}$.

The calixarene resist films on Si substrate with a thickness of $11.8 \mathrm{~nm}$ to $16.9 \mathrm{~nm}$, which were controlled by the spin coating at a speed of $3000 \mathrm{rpm}$ to $8000 \mathrm{rpm}$ for $190 \mathrm{~s}$ was prepared as shown in Fig. 4. 3. The thicknesses were measured by contact mode atomic force microscope (AFM).

The resist process is as follows. After coating the resist on the Si substrate, pre-baking was done at the $110{ }^{\circ} \mathrm{C}$ for $3 \mathrm{~min}$ in air. Then, the EB drawing was done by raster scanning with the CAD data. After the developing and rinsing with a developer of ZEP-RD and isopropanol, respectively, The pattern quality was checked whether complete formation of the drawn dot arrays was done or not.

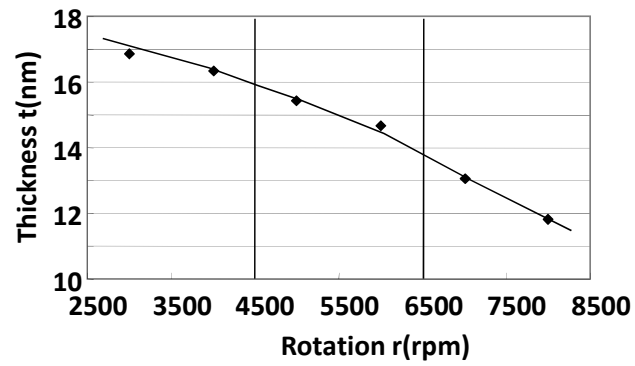

Fig. 4.3. Thicknesses of $11.8 \mathrm{~nm}$ to $16.9 \mathrm{~nm}$ controlled by the spin coating at a speed of 3000 rpm to $8000 \mathrm{rpm}$

\subsection{Experimental results}

\subsubsection{Formation of $20 \mathrm{~nm} \times 20 \mathrm{~nm}$ pitched dot arrays [16]}

Figure 4.4 shows the SEM images of $20 \mathrm{~nm} \times 20 \mathrm{~nm}$ pitch dot arrays patterns drawn by $30 \mathrm{keV}$ electron beam at a dosage of $16 \mathrm{mC} / \mathrm{cm}^{2}$ using various resist thicknesses of 11.8 to $16.3 \mathrm{~nm}$. In Figs. 4. 4(a) and (b), there are many defects such as the dots combined with neighbor dots. On the other hand, the number of defect decreases with the thickness. At the resist thickness of $13.1 \mathrm{~nm}$, the $20 \mathrm{~nm} \times 20 \mathrm{~nm}$ pitch dot array have completely been drawn as shown in Fig. 4 . 4(c). Furthermore, using further thin resist film, the dot arrays appear unclearly (Fig. 4. 4(d)) because the SEM contrast becomes poor due to thin thickness. Therefore, the resist thickness of about $13 \mathrm{~nm}$ is very suitable for formation of $20 \mathrm{~nm} \times 20 \mathrm{~nm}$ very fine pitch dot arrays.
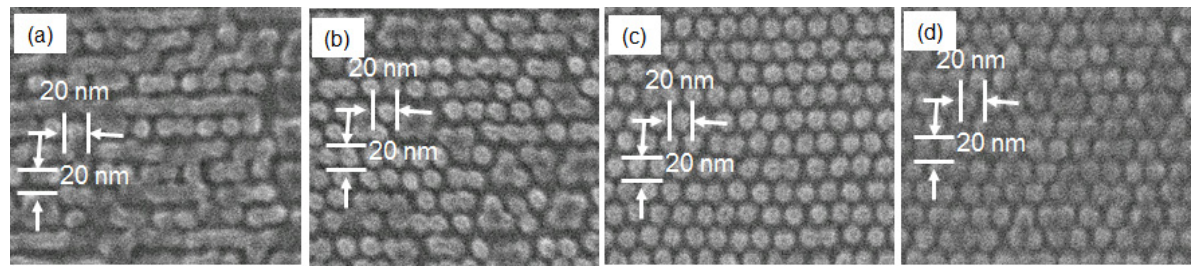

Fig. 4.4. SEM images of $20 \mathrm{~nm} \times 20 \mathrm{~nm}$ fine pitch dot arrays formed by $30 \mathrm{keV}$ EB lithography at a dosage of $16 \mathrm{mC} / \mathrm{cm}^{2}$, (a) with a resist thickness of $16.1 \mathrm{~nm}$, (b) 14.7 , (c) $13.1 \mathrm{~nm}$ and (d) $11.8 \mathrm{~nm}$. 


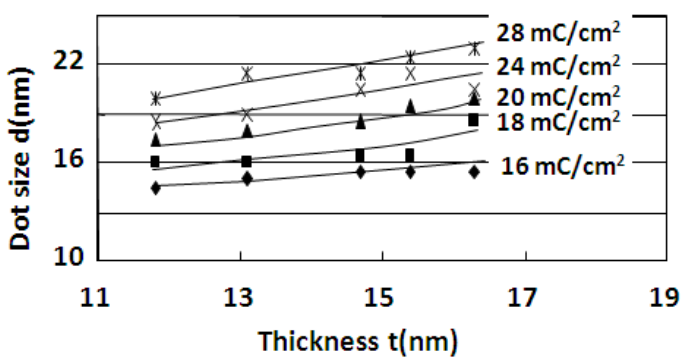

Fig. 4.5. Variations of average calixarene dot size with thicknesses for various exposure dosages.

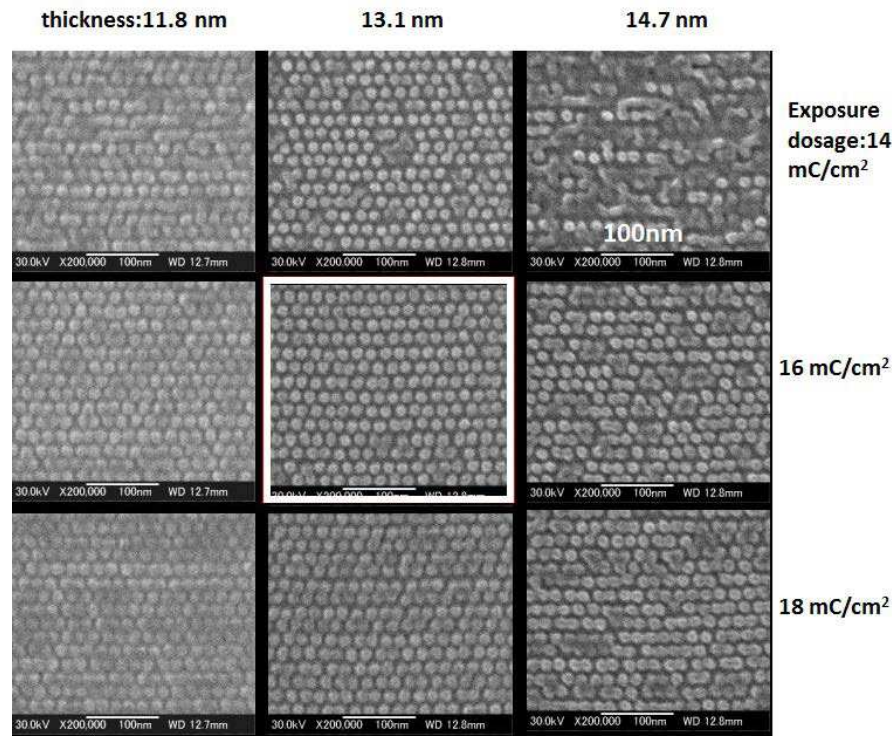

Fig. 4.6. SEM images of $20 \mathrm{~nm} \times 20 \mathrm{~nm}$ pitched calixarene resist dot arrays formed by $30 \mathrm{keV}$ EB drawing on Si substrate $\left(1.6 \mathrm{~Tb} / \mathrm{in}^{2}\right)$ in 9 shots/dot drawing.

From Fig. 4. 4, the variations of average calixarene dot size for various thicknesses and exposure dosages were obtained as shown in Fig. 4. 5. The figure shows that the dot diameter decreases with not only thickness but also exposure dosage. Although the diameter variation with exposure dosage means that proximity effect occurs in the EB writing, the thin resist layer contributes to get small drawing probe. In order to draw the 20 $\mathrm{nm} \times 20 \mathrm{~nm}$ pitch dot arrays pattern, we need a dot size of $15 \mathrm{~nm}$ at least. From Fig. 4. 5, it is neccessary to choose an exposure dosage of $<16 \mathrm{mC} / \mathrm{cm}^{2}$ and a resist thickness of $<13 \mathrm{~nm}$ for the fine pitch arrays formation.

Figure 4.6 shows the result of the $20 \mathrm{~nm} \times 20 \mathrm{~nm}$ pitch dot arrays patterns drawing with a thickness of 11.8-14.7 $\mathrm{nm}$ at some exposure dosages. The exposure dosages were 14 $\mathrm{mC} / \mathrm{cm}^{2}, 16 \mathrm{mC} / \mathrm{cm}^{2}$ and $18 \mathrm{mC} / \mathrm{cm}^{2}$. At a dosage of $14 \mathrm{mC} / \mathrm{cm}^{2}$, there are some vacancies as defects. It may be caused by that the dosage is not enough to make the resist molecular link. When using commercial developer, the insufficient exposed resist part was solved so 
that the completed dots could not be formed. At a dosage of $16 \mathrm{mC} / \mathrm{cm}^{2}$, it is enough to makes complete dots. In a case of a dosage of $18 \mathrm{mC} / \mathrm{cm}^{2}$, the dot was combining together with neighbor dots because the dot size becomes larger than that at $16 \mathrm{mC} / \mathrm{cm}^{2}$. Figure 4.7 shows the variations of the dot size with exposure dosage of the $20 \mathrm{~nm} \times 20 \mathrm{~nm}$ dot arrays pattern at a resist thickness of $13.1 \mathrm{~nm}$. The fluctuation of the dot size between minimum and maximum dot sizes are about $3 \mathrm{~nm}$. This is as small as that in previous section. The experimental results demonstrated that $30 \mathrm{keV}$ EB drawing can form $20 \mathrm{~nm} \times 20 \mathrm{~nm}$ very fine pitch dot arrays pattern using optimal resist thickness and exposure dosage.

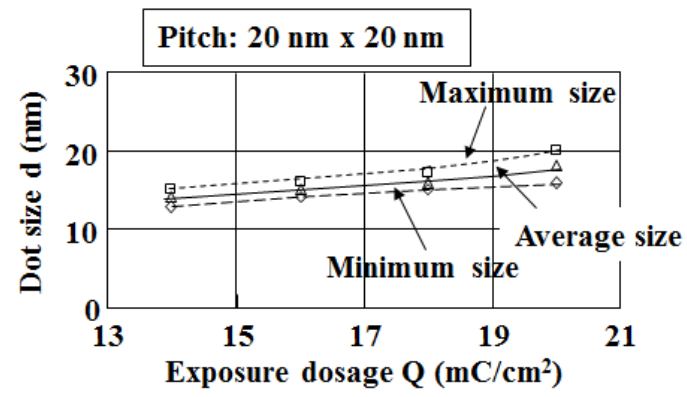

Fig. 4.7. Variation of the resist dot size measured from the $20 \mathrm{~nm} \times 20 \mathrm{~nm}$ pitch resist dot arrays formed by EB-drawing with $30 \mathrm{keV}$ incident electron.

\subsubsection{Challenge to form $18 \mathrm{~nm} \times 18 \mathrm{~nm}$ pitched dot arrays [5, 16]}

(1) Dependences of resist thickness and exposure dosage on 20-nm-pitch EB drawing

Initially, we studied the effects of resist thickness and exposure dosage on 30-keV EB drawing of the dot arrays with a pitch of $20 \mathrm{~nm} \times 20 \mathrm{~nm}$. Figure 4.6 indicates that the optimal thickness and exposure dosage were about $13.1 \mathrm{~nm}$ and $16 \mathrm{mC} / \mathrm{cm}^{2}$, respectively. On the other hand, we did not obtain good results using a thickness of $11.8 \mathrm{~nm}$, although the thickness was as thin as possible. This may be caused by insufficient contrast of SEM images due to an excessively thin resist and poor focus adjustment. Thus, it is necessary to use a thin resist film to suppress the scattering of the primary electrons in the resist. The tendency that finer dot arrays patterns can be drawn with thinner resists are demonstrated, and agrees with the simulation result. Nevertheless, there exists a critical thickness for fine evaluation of the drawn pattern as described above.

\section{(2) Possibility of forming $18 \mathrm{~nm}$ pitch dot arrays pattern}

To anticipate the ultimate pitch of the dot arrays using 30-keV EB drawing, we studied the EB drawing margin by EB drawing of highly packed dot arrays with pitches of $20 \times 20,25 \times$ 25 , and $30 \times 30 \mathrm{~nm}^{2}$ by ranging the exposure dosages between 14 and $40 \mathrm{mC} / \mathrm{cm}^{2}$. Figure 4 . 8 shows the SEM images of the $20 \times 20,25 \times 25$, and30 $\times 30 \mathrm{~nm}^{2}$ pitch dot arrays patterns formed using various dosages at a constant resist thickness of $13.1 \mathrm{~nm}$. The experimental results indicate that the optimal condition for drawing becomes narrow as dot packing increases. We successfully formed $20 \times 20 \mathrm{~nm}^{2}$ pitch dot arrays at an exposure dosage of 16 $\mathrm{mC} / \mathrm{cm}^{2}$. In contrast, the available proper exposure dosages increased to 14-22 and 14-30 $\mathrm{mC} / \mathrm{cm}^{2}$ for the pitchs of $25 \times 25$ and $30 \times 30 \mathrm{~nm}^{2}$, respectively. The results show that it is very difficult to form $20 \times 20 \mathrm{~nm}^{2}$ pitch dot arrays in the resist film on Si substrates even 
when a thinner resist film on Si substrate was used in the 30-keV-EB drawing. Nevertheless, a complete $20 \mathrm{~nm} \times 20 \mathrm{~nm}$ pitch dot array was successfully achieved using the unique EB drawing condition for EB drawing with a resist thickness of $13.1 \mathrm{~nm}$ and an exposure dosage of $16 \mathrm{mC} / \mathrm{cm}^{2}$ as described above. The exposure dosage is dependent on dot pattern data. In the experiment, we used the dot pattern data of $3 \times 3$ shots/dot. We have also indicated the exposure dosage with a unit of C/dot, as shown in Fig. 4. 9.

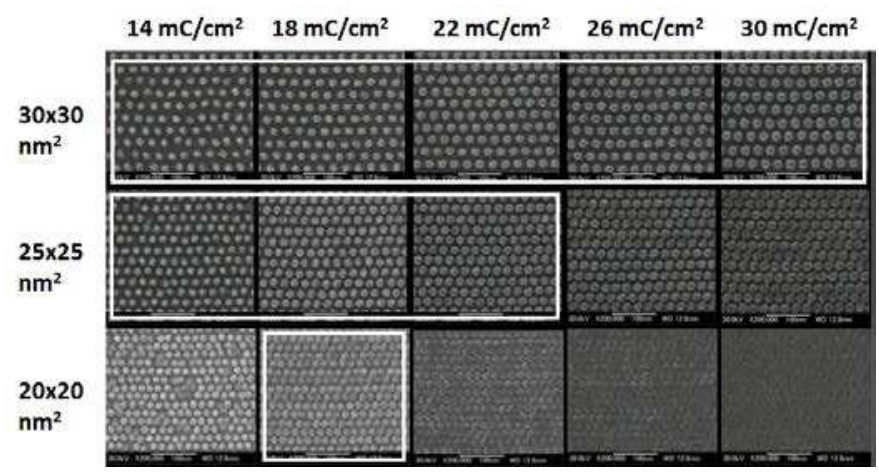

Fig. 4.8. SEM images of $20 \times 20,25 \times 25,30 \times 30 \mathrm{~nm}^{2}$ pitched calixarene resist dot arrays formed by $30 \mathrm{keV}$ EB drawing on 13.1-nm-thick resist film on Si substrate.

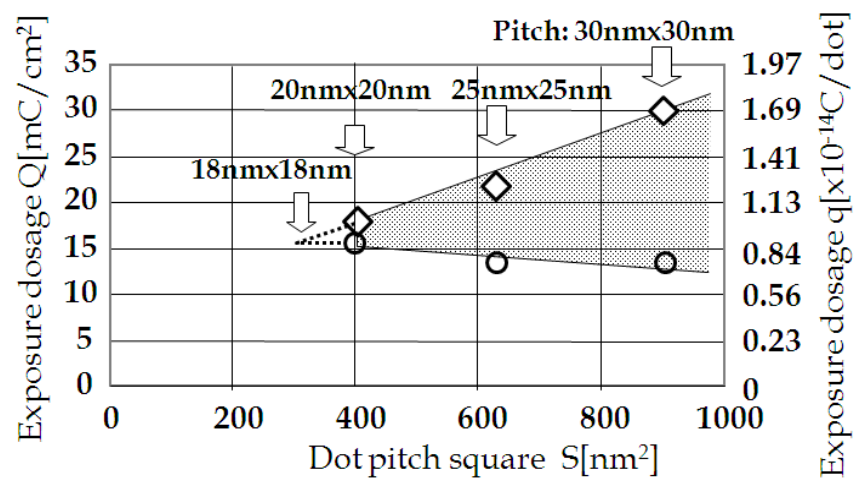

Fig. 4.9. A proper region of 30-keV-EB drawing available for very fine pitch dot arrays in a relationship between exposure dosage and unit cell area (square pitch) in 9 shots/dot drawing.

From the above results, we can obtain an available drawing margin with regard to dot packing and exposure dosage for $30-\mathrm{keV}$ EB drawing. The margin indicates that a minimum pitch exists for 30-keV EB drawing of the dot array pattern. In the 30-keV EB drawing and calixarene resist system, the smallest pitch is about $18 \times 18 \mathrm{~nm}^{2}$. The dosage margin of about $6 \%$ is estimated at the pitch. This means that we need a stable EB-drawing system including the EB source, resist material and its thickness. Figure 4.10 shows that there is the possibility of forming $18 \times 18 \mathrm{~nm}^{2}$ pitch dot arrays using EB drawing. Our results demonstrate that $18 \times 18 \mathrm{~nm}^{2}$ pitch dot arrays can be partially drawn. It is clarified that the 
30-keV EB drawing has the potential to form $18 \times 18 \mathrm{~nm}^{2}$ pitch dot array patterns in thinner resist films on Si substrates by accurately selecting the optimum EB drawing conditions. For the formation of complete dot arrays pattern with $18 \times 18 \mathrm{~nm}^{2}$ pitch, stability in the EB system is also required. At least, we have to use stable electron probe current with a deviation within $6 \%$ for $2 \mathrm{Tbit} / \mathrm{in}^{2}$ magnetic storage using 30-keV EB drawing.

The exposure dosages were $10-11 \mathrm{mC} / \mathrm{cm}^{2}$, which are smaller than the dosage estimated in $18 \times 18 \mathrm{~nm}^{2}$ pitch drawing (Fig. 4.9). The small exposure dosages are caused by using different exposure shot numbers per square pattern as a dot. In Fig. 4. 10, we increased the number of shots/dot from 9 to $16(4 \times 4)$ for fast EB drawing. The dosage of $10 \mathrm{mC} / \mathrm{cm}^{2}$ in 16 shots/dot drawing corresponds to about $18 \mathrm{mC} / \mathrm{cm}^{2}$ in 9 shots/dot drawing. The 18 $\mathrm{mC} / \mathrm{cm}^{2}$ almost agrees with the estimated dosage in Fig. 4. 9.

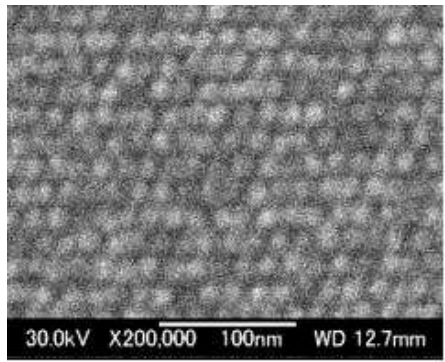

(a) $10 \mathrm{mC} / \mathrm{cm}^{2}$

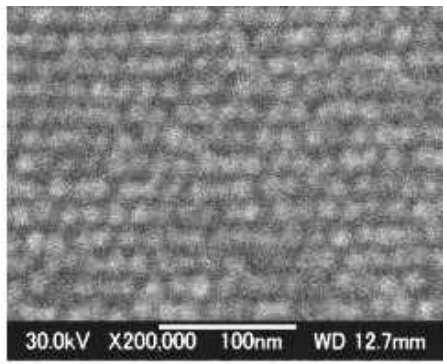

(b) $11 \mathrm{mC} / \mathrm{cm}^{2}$

Fig. 4.10. SEM images of $18 \times 18 \mathrm{~nm}^{2}$ pitched resist dot arrays formed by $30 \mathrm{keV}$ EB drawing on Si substrate (about $2.0 \mathrm{~Tb} / \mathrm{in}^{2}$ ).

\subsubsection{Small proximity effect using calixarene resist [17]}

The proximity effect of the EB drawing and thinner calixarene resist system is considered using the EID in the experiment and the EDD in Monte Carlo simulation.

Assuming that the EID function is defined with 2 Gaussian distributions as described in previous section, the $1^{\text {st }}$ and $2^{\text {nd }}$ terms in Eq. (3. 1) represent the energy depositions due to electron forward scattering (FS) and backward scattering (BS), respectively. For the miniaturization of the bit size, very small proximity effect and small $\sigma_{1}$ and $\sigma_{2}$ values are crucial. The ratio $\eta$ of the total energies due to FS and BS is very important.

$$
\eta=\int C_{1} \exp \left(-\frac{r^{2}}{\sigma_{1}{ }^{2}}\right) d r / \int C_{2} \exp \left(-\frac{r^{2}}{\sigma_{2}{ }^{2}}\right) d r=\left(\frac{C_{2}}{C_{1}}\right)\left(\frac{\sigma_{2}}{\sigma_{1}}\right)^{2}
$$

The $\eta$ value has to be less than 1 because the drawing energy due to FS becomes dominant for very fine dot arrays formation. On the other hand, considering EB drwing of square, the drawing energy due to BS at side and corner of the square becomes a half and a quarter of that at center, respectively, based on reciprocity principle [9]. The variation of BS drawing energy on exposure dosage at everywhere of the drawing area is suppressed to be negligible small if the $\eta$ value is less than 1 .

In the experiments, the exposure dosages were changed from $10 \mu \mathrm{C} / \mathrm{cm}^{2}$ to $5 \mathrm{C} / \mathrm{cm}^{2}$. We obtained the EID using calixarene as shown in Fig. 4. 11(a) [23]. When we roughly fit the EID 
function to Eq. (3.1), the $\sigma_{1}, \sigma_{2}, C_{1} / C_{2}$, and $\eta$ values are about $5 \mathrm{~nm}, 15 \mathrm{~nm}, 0.03$ and 0.27 , respectively. In the Monte Carlo simulation, we obtained EDD in 15-nm-thick resist on Si substrate (Fig. 4. 11(b)). When roughly fitting it to the EID function, they are about $2 \mathrm{~nm}, 10$ $\mathrm{nm}, 0.02$ and $0.5 \mathrm{~nm}$, respectively. Although the resist materials are difficult in the experiments and simulations, the values of $\sigma_{1}, \sigma_{2}, C_{1} / C_{2}$ in the experiment are almost same as those in the simulation. Comparing between experimental and simulated results, the values of $\sigma_{1}$ in both cases agree well because the electron probe size of $2 \mathrm{~nm}$ and the resist molecular size of $1 \mathrm{~nm}$ can be considered in the EB drawing. According small $\sigma_{1}$ and $\eta$ values, the system is very suitable for very fine dot and very fine pitch dot arrays drawing. Figures 4.12(a)-(d) show SEM images of very fine pitch resist dot arrays on Si substrate with various pitches of $20 \times 20 \mathrm{~nm}^{2}$ to $40 \times 40 \mathrm{~nm}^{2}$. The exposure dosage was $16 \mathrm{mC} / \mathrm{cm}^{2}$. In these experiments, we succeeded in obtaining the highest-packed dot array pattern with a pitch of $20 \times 20 \mathrm{~nm}^{2}$ (Fig. 4. 12(a)), which corresponds to the ultrahigh recording density of about $1.61 \mathrm{~Tb} / \mathrm{in}^{2}$ in patterned media. The dot sizes of about 12.5 to $18 \mathrm{~nm}$ are changed as shown in Fig. 4. 12(e). The size fluctuation is about $2 \mathrm{~nm}$ and almost constant in a range of 0.4 to $1.6 \mathrm{~Tb} / \mathrm{in}^{2}$. This shows that the drawings are carried out in no relation with the dot pitch. Figures 4. 13(a) and (b) show SEM images of $25 \times 25 \mathrm{~nm}^{2}$ pitched resist dot arrays at side and corner of the drawing area Fig. 4.13 SEM images (a), (b) and histograms (c)-(e) of $25 \mathrm{~nm} \times 25 \mathrm{~nm}$ pitch resist dot arrays on Si substrate at a dosage of $16 \mathrm{mC} / \mathrm{cm}^{2}$, (a) at side of the written pattern area, (b) at corner, (c) at center, (d) at side and (e) at corner.at an exposure dosage of $16 \mathrm{mC} / \mathrm{cm}^{2}$.

at an exposure dosage of $16 \mathrm{mC} / \mathrm{cm}^{2}$. The dot sizes histograms are shown in Figs. 4.13 (c)(e). Comparing the distributions at center, side and corner of the drawing area, the histograms and the mean values are almost same. These experimental results demonstrate the proximity effect is extremely small in this system. The system is suitable for formation of very fine pitch dot arrays with very fine dot. From the results, a curvature of corner in the drawing pattern could be sharp shape with a radius of 7-8 $\mathrm{nm}$.

In addition, using $50 \mathrm{keV}$ EB lithography, we can consider that the $\sigma_{1}$ and $\eta$ values will be improved small to a twice of those in $30 \mathrm{keV}$ EB lithography. This is because the forward scattering area in $50 \mathrm{keV}$ EB lithography is suppressed to a twice of that in $30 \mathrm{keV} \mathrm{EB}$ lithography. Therefore, $50 \mathrm{keV}$ lithography is more suitable for fine dots patterning than 30 keV EB lithography.
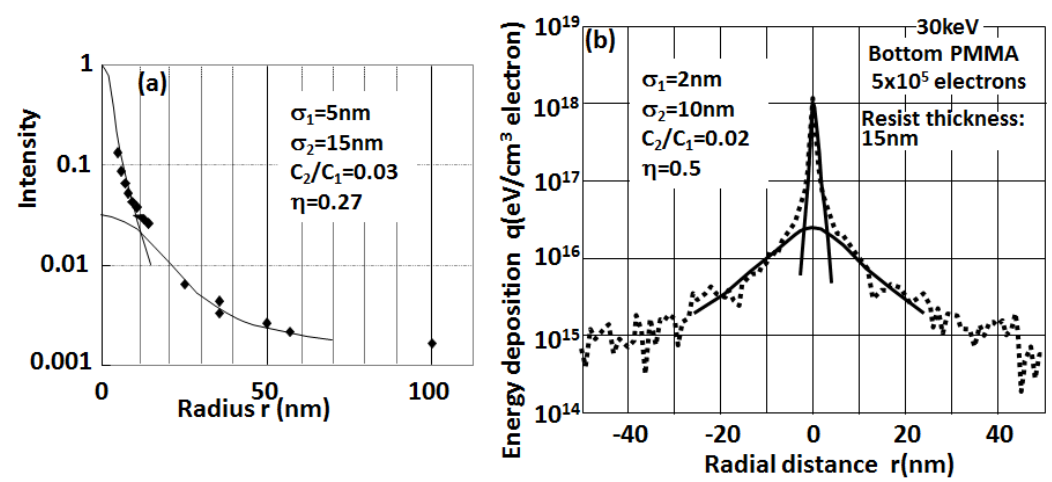

Fig. 4.11. Experimental result (a) and Monte Carlo calculation (b) of EID function and roughly fitting to EID function in $30 \mathrm{keV}$ EB drawing and $15 \mathrm{~nm}$ thick calixarene resist on Si substrate. 
The EB writing with thin calixarene resist promises to open the way toward ultrahighdensity recording at $>1 \mathrm{~Tb} /$ in $^{2}$ and quantum devices.
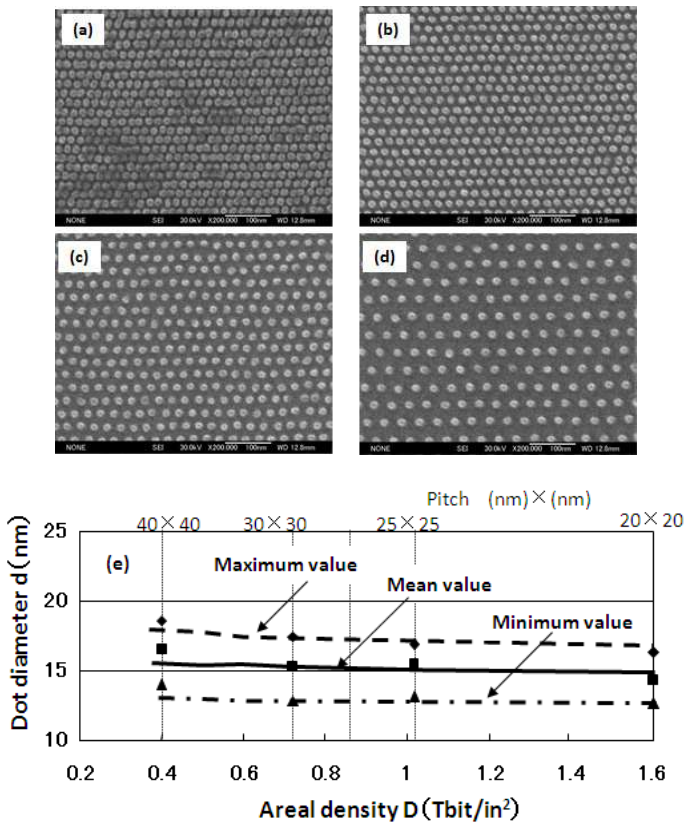

Fig. 4.12. SEM images (a)-(d) and the dot size variation (e) of very fine pitch resist dot arrays at center of the drawing area on Si substrate at a dosage of $16 \mathrm{mC} / \mathrm{cm}^{2}$ with a pitch of (a) 20 $\mathrm{nm} \times 20 \mathrm{~nm}$, (b) $25 \mathrm{~nm} \times 25 \mathrm{~nm}$, (c) $30 \mathrm{~nm} \times 30 \mathrm{~nm}$ and (d) $40 \mathrm{~nm} \times 40 \mathrm{~nm}$.
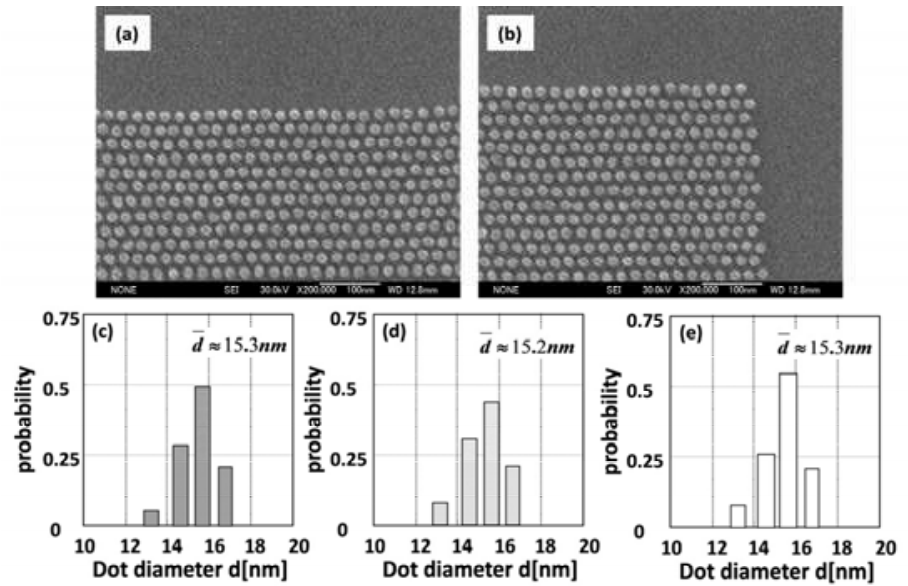

Fig. 4.13. SEM images (a), (b) and histograms (c)-(e) of $25 \mathrm{~nm} \times 25 \mathrm{~nm}$ pitch resist dot arrays on Si substrate at a dosage of $16 \mathrm{mC} / \mathrm{cm}^{2}$, (a) at side of the written pattern area, (b) at corner, (c) at center, (d) at side and (e) at corner. 


\section{Application of EB drawing to formation of nano-Si-dot and nano-polymer- pit arrays with a pitch of $25 \mathrm{~nm} \times 25 \mathrm{~nm}$ using EB drawing, reactive ion etching (RIE) and nano-imprinting [23, 25]}

The possibility of forming very fine pits or dots with a pitch of less than $25 \mathrm{~nm}$ was researched using reactive ion etching (RIE) and nano-imprinting with EB drawn pattern as a mask for the future process. We were able to fabricate ultrahighly packed dot arrays with a dot diameter of less than $15 \mathrm{~nm}$ and a dot pitch of $25 \mathrm{~nm} \times 25 \mathrm{~nm}$ in negative calixarene resist using EB drawing. We also formed nan-Si dot arrays patterns by $\mathrm{CF}_{4}$ RIE. Furthermore, pit arrays were formed in polymer film through nano-imprinting by the photo-polymer method using a Si dot arrays pattern as the master mold. We demonstrated that the EB-drawn dot arrays resist pattern is very suitable for the fabrication of Si dot arrays and pit arrays with a pitch of $25 \mathrm{~nm} \times 25 \mathrm{~nm}$ in this polymer. The Si dot and pit diameters were less than $10 \mathrm{~nm}$.

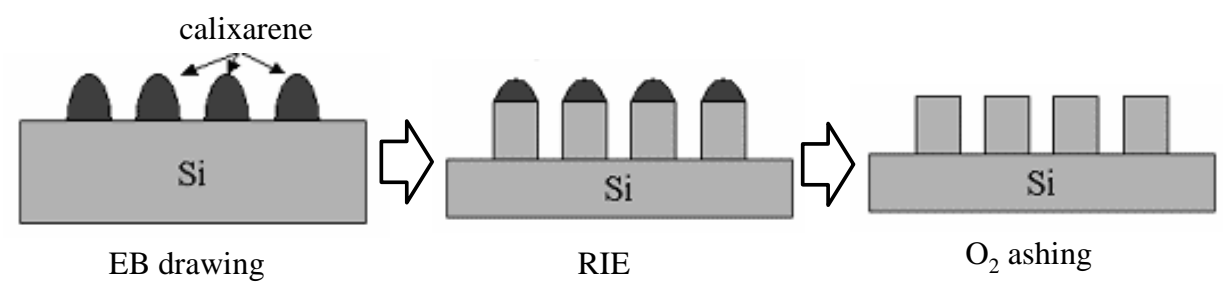

Fig. 5.1. Process flow for Si nano-dot arrays by RI etching and ashing.

\subsection{Dry etching (RIE and ashing)}

We tried to apply the EB drawing to dry etching process. We checked if the pattern is available for reactive ion etching (RIE) process, and we carried out $\mathrm{CF}_{4}$-RIE using the resist patterns. We performed to do RIE of the Si substrate with the resist dot arrays pattern after post baking of the resist pattern, and to remove the remained resist by $\mathrm{O}_{2}$ ashing. The process flow is shown in Fig. 5. 1. The experiments conditions are represented in Table 5. 1.

\begin{tabular}{|l|l|l|}
\hline & $\mathrm{RIE}$ & Ashing \\
\hline gas & $\mathrm{CF}_{4}$ & $\mathrm{O}_{2}$ \\
\hline flow rate & $5 \mathrm{sccm}$ & $10 \mathrm{sccm}$ \\
\hline pressure & $1 \mathrm{mTorr}$ & $2.5 \mathrm{mTorr}$ \\
\hline bias & $-60 \mathrm{~V}$ & $-120 \mathrm{~V}$ \\
\hline Etching time & $0.5-2 \mathrm{~min}$ & $10 \mathrm{~min}$ \\
\hline
\end{tabular}

Table 5.1. RIE and ashing conditions for Si dot formation and resist removal, respectively.

As the experimental results, we obtained very fine $\mathrm{Si}$ dot arrays with a pitch of $30 \mathrm{~nm} \times 25$ $\mathrm{nm}$ to $25 \mathrm{~nm} \times 25 \mathrm{~nm}$ (Fig. 5. 2). The minimum diameter of the Si dot is $<10 \mathrm{~nm}$, and the height is about $20 \mathrm{~nm}$. Figure 5.3 shows histograms of the EB drawn resist dot and the RIE Si dot sizes in a pitch of $25 \mathrm{~nm} \times 25 \mathrm{~nm}$. According RIE and ashing, the resist dot size is 
transferred to Si substrate. Mean dot size decreases from about $14.6 \mathrm{~nm}$ to about $9 \mathrm{~nm}$. This may be caused by in-plane etching in RIE. On the other hand, the standard deviation increases from about $1.3 \mathrm{~nm}$ to about $1.5 \mathrm{~nm}$. Although the cause is not clear, it may be due to the EB resist toughness or the resist pattern edge sharpness. From the etching experiments, we measured the etching rates of $7 \mathrm{~nm} / \mathrm{min}$ and $10 \mathrm{~nm} / \mathrm{min}$ in calixarene and $\mathrm{Si}(100)$ in normal direction, respectively, as shown in Fig. 5. 4. The etching rate in plane component is about $2 \mathrm{~nm} / \mathrm{min}$. The data supported the dot size decrease.

\section{Before RIE}

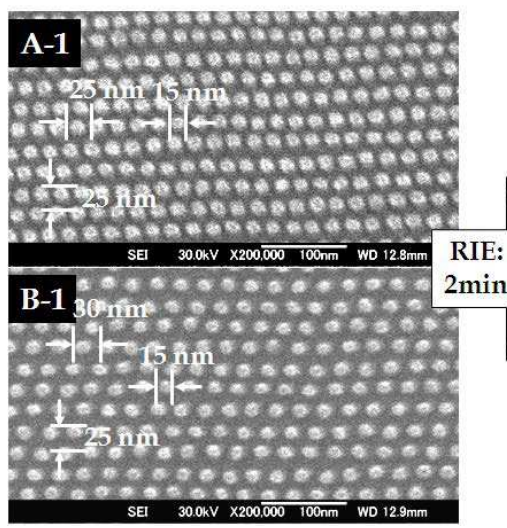

After RIE and ashing

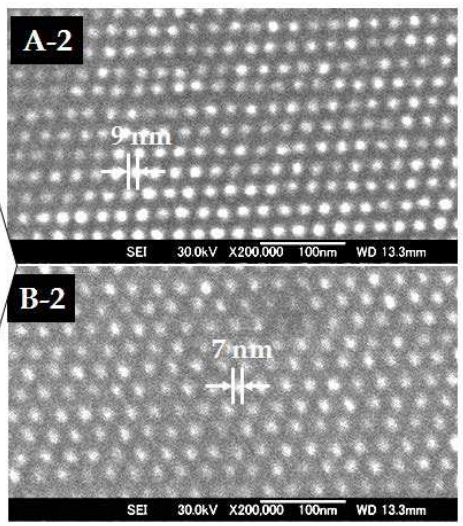

Fig. 5.2. Dot arrays patterns before and after RIE and ashing (SEM images; A: $25 \mathrm{~nm} \times 25 \mathrm{~nm}$ in pitch and B: $25 \mathrm{~nm} \times 30 \mathrm{~nm}$.

$\sigma: 1.5 \mathrm{~nm} \quad \sigma: 1.3 \mathrm{~nm}$

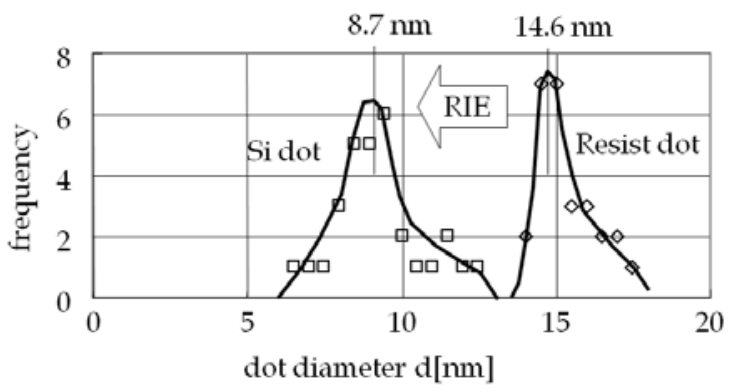

Fig. 5.3. Histograms of the resist and Si dot diameters before and after RIE and ashing, respectively, with a pitch of $25 \mathrm{~nm} \times 25 \mathrm{~nm}$. 


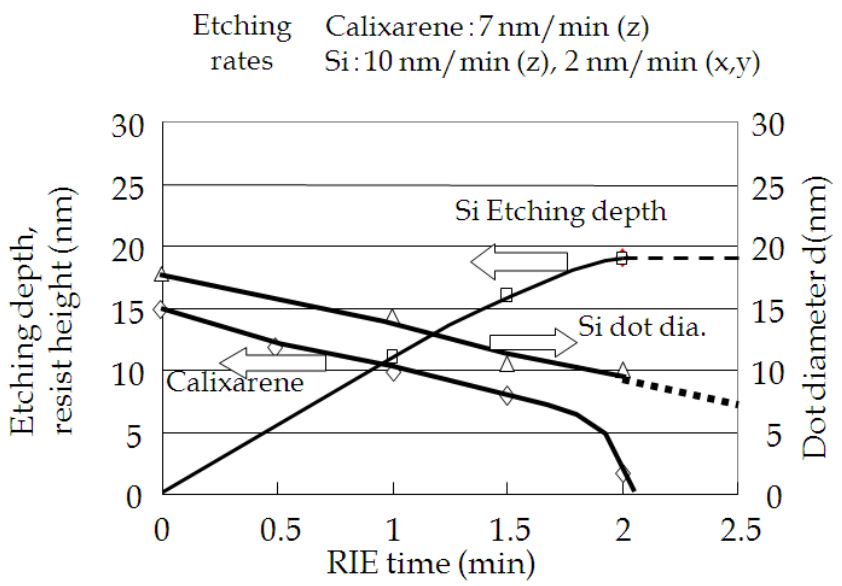

Fig. 5.4. Etching rates of Si, calixarene resist and Si dot diameter using RIE.

\subsection{Nano-imprinting using UV photo polymer}

By using the RIE Si dot arrays pattern as a mold, we tried to do nano-imprinting (NIP) to transfer the etched Si dot arrays pattern into UV photo polymer. Figure 5. 5 shows the nano-imprinting process flow with UV photo polymer method. After coating the polymer on the dot arrays, putting the polycarbonate substrate on the polymer and illuminating the UV light into the polymer, we obtained ultrahigh packed pit arrays in the polymer as shown in Fig. 5. 6. We could demonstrate to fabricate the $25 \mathrm{~nm} \times 25 \mathrm{~nm}$ pitch pit arrays using EB drawing, RIE and NIP, although the polymer surfaces are in slight curvature because of deformation in the SEM observation or localized stretching in separating the polymer from the mold. From SEM images of the Si mold with $25 \mathrm{~nm} \times 25 \mathrm{~nm}$ pitch Si dot arrays before and after NIP, we have confirmed that it is clear that the mold surface has no damage after NIP. From the SEM images of Figs. 5. 3 and 5. 6, we observed that the pit diameters are about $2 \mathrm{~nm}$ larger than those in the $\mathrm{Si}$ dots. We can consider that the polymer have a shrink property with a rate of about $8 \%$ in the fixing process. In a detail, however, the rate of $8 \%$ does not agree with the increase of about $2 \mathrm{~nm}$ against mean dot diameter of about $9 \mathrm{~nm}$. We should consider the shrinkage in the future. We clarified that the very fine pitch resist dot arrays pattern written by EB drawing with calixarene are available for dry etching and nano-imprinting process. We demonstrated to form the Si nano-dot and pit arrays with a pitch of $25 \mathrm{~nm} \times 25 \mathrm{~nm}$ using RIE and nano-imprinting with the resist pattern as a mask. 


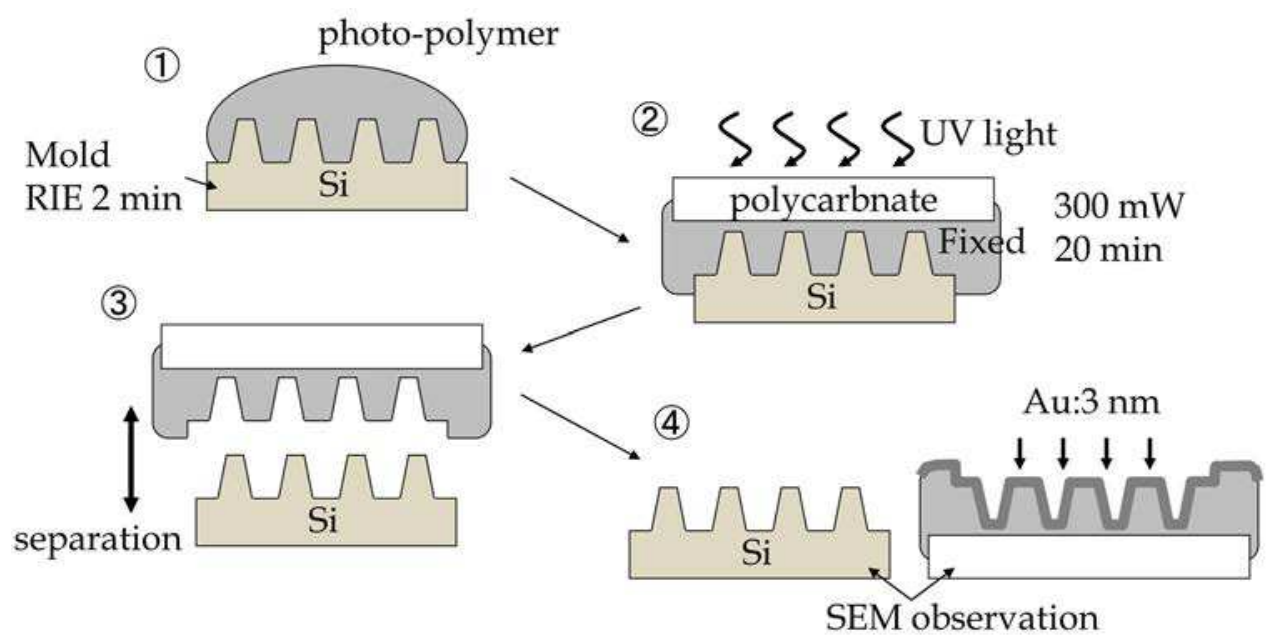

Fig. 5.5. Process flow of $2 \mathrm{P}$ (photo polymer) method for nano-imprinting.
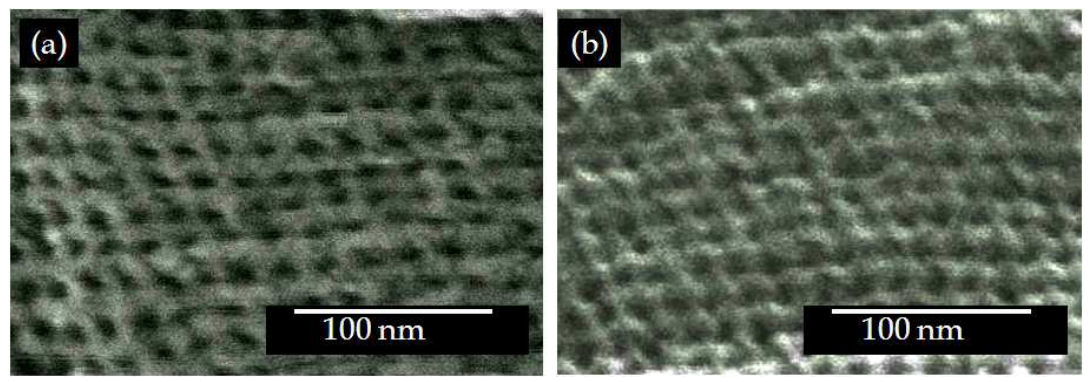

Fig. 5.6. SEM images of very fine pitch pit arrays in photo-polymer using nano-imprinting with the Si mold made by RI etched Si dot arrays pattern with a pitch of $25 \mathrm{~nm} \times 25 \mathrm{~nm}$ drawn by $30 \mathrm{keV}$ electrons with exposure dosages, (a) $28 \mathrm{mC} / \mathrm{cm}^{2}$, (b) $36 \mathrm{mC} / \mathrm{cm}^{2}$.

\section{Conclusion}

I have described an electron beam (EB) lithography using a raster drawing for fabrication of nanometer sized dot or pit arrays, theoretically and experimentally. I considered the possibility to form the nanometer-sized pitch fine dot arrays by the energy deposition distribution (EDD) calculated by the home-made Monte Carlo simulation. The experimental research is done by dependences of 2 resist materials (ZEP520 and calixarene) and thickness on the drawn dot size and pitch in EB drawing. I have used a conventional EB drawing system based on high resolution-scanning electron microscope (HR-SEM). As results using both positive and negative resists with thin thickness. I can demonstrate the possibility to form nanometer-sized dot and fine pitched dot arrays as follows.

1. The simulation shows that the EDD profile seems to be cone shape, which is very suitable for formation of nanometer-sized dots using negative resist, while it is not suitable in a case of using positive resist. 
2. It is demonstrated that the calixarene negative resist is very suitable to form an ultrahigh packed bit arrays pattern, comparing with ZEP520 positive resist.

3. As the experimental results, the minimum pitch of about $18 \mathrm{~nm} \times 18 \mathrm{~nm}$ has been demonstrated using 30-keV EB drawing with calixarene resist, while about $40 \mathrm{~nm} \times 50$ $\mathrm{nm}$ pitch has been demonstrated with ZEP520.

4. EB drawing with calixarene has extremely small proximity effect.

5. It is demonstrated that nanometer-sized $\mathrm{Si}$ dot arrays were fabricated by $\mathrm{CF}_{4}-\mathrm{RI}$ etching using calixarene resist dot arrays as a mask.

6. It is also demonstrated that nanometer-sized polymer pit arrays were fabricated by nano-imprinting with $2 \mathrm{P}$ method using the nanometer-sized Si dot arrays as a mother pattern.

Furthermore, we try to form $15 \mathrm{~nm} \times 15 \mathrm{~nm}$ pitched resist dot arrays using HSQ negative EB resist. We have gotten a prospect to form them by improving a developer for the resist. There are some papers to improve them using HSQ negative resist. X. Yang et al. have reported $12 \mathrm{~nm} \times 12 \mathrm{~nm}$ or $15 \mathrm{~nm} \times 15 \mathrm{~nm}$ pitch fine resist dot arrays using $100 \mathrm{keV} \mathrm{EB}$ drawing with hot developer of TMAH at $40{ }^{\circ} \mathrm{C}$ [6]. In addition, J. K. Yang et al. have reported $12 \mathrm{~nm}$ or $14 \mathrm{~nm}$ pitch resist line and space pattern EB-drawn using $100 \mathrm{keV} \mathrm{EB}$ drawing with salty development [27].

On the other hand, it is crucial to improve the resolution of SEM to check whether the EBdrawn pattern is complete or not. We should get high resolution observation method for very fine pitch dot arrays with a pitch of less than $15 \mathrm{~nm} \times 15 \mathrm{~nm}$.

\section{Acknowledgements}

I would like to thank Profs. H. Sone, Y. Yin, K. Itoh, Z. Mohamad and T. Tamura, and students of Ms. H. Zhang, Mr. H. Sano, Mr. M. Shirai in Hosaka labo of Gunma University for the experiments, simulation and fruitful discussion, and Mr. K. Noguchi in Dept. of Electronic Eng., Gunma University for technical supports in EB writing and resist process. This research was performed in Kiryu Ohta Toshi Area project supported by the Ministry of Monbukagaku-sho of Japan.

\section{References}

[1] J. A. Dohery, Solid State Technol. 2283 (1979).

[2] E. V. Weber and R. D. Moor, J, Vac. Sci. Technol. 16, 1780 (1979).

[3] G. Varnell, D. Spiecer, J. Hebley, R. Robbins, C. Carpenter and M. Malone, J. Vac. Sci. Technol. 16, 1787 (1979).

[4] S. Hosaka, M. Ichihashi, H. Hayakawa, S. Nishi and M. Migitaka, Jpn. J. Appl. Phys. 21, 543 (1982).

[5] S. Hosaka, Y. Tanaka, M. Shirai, Z. Mohamad and Y. Yin, Jpn. J. Appl. Phys. 49, 046503 (2010).

[6] X. Yang, S. Xiao, et al., J. Vac. Sci. Technol. 25, 2202 (2007).

[7] S. Hosaka, H. Sano, K. Itoh, and H. Sone, Microelectronic Eng. 83, 792 (2006).

[8] H. Zhang, T. Tamura, Y. Yin, and S. Hosaka, Key Engineering Material, to be published.

[9] T. H. P. Chang, J. Vac. Sci. Technol. 12, 1271 (1975).

[10] W. Zhang, A. Potts, D.M. Bagnall, B.R. Davidson, Thin Solid Film 515, 3714 (2007).

[11] K. Murata and T. Matsukawa, Jpn. J. Appl. Phys. 10, 678(1971). 
[12] L.M. Ren, B.Q. Chen, and Z.Y. Tan, Opto-Electronic Engineering, 29, 24 (2002).

[13] S. Hosaka, H. Sano, M. Shirai, Y. Yin, and H. Sone, Microelectronics Eng. 84, 802 (2007).

[14] J. Fujita, Y. Ohnishi, S. Manako, Y. Ochiai, E. Nomura, T. Sakamoto, and S. Matsui, Jpn. J. Appl. Phys. 36, 7769 (1997).

[15] M. Ishida, J. Fujita, T. Ogurai, Y. Ochiai, E. Ohshima, and J. Momoda, Jpn. J. Appl. Phys. 42,3913 (2003).

[16] Z. Mohamad, M. Shirai, H. Sone, S. Hosaka, and M. Kodera, Nanotechnology 19, 125301 (2008).

[17] S. Hosaka, Z. Mohamad, M. Shirai,H. Sano, Y. Yin, A. Miyachi, and H. Sone, Appl. Phys. Express 1, 027003 (2008).

[18] C.T. Rittner, M.E. Best, B.D. Terris, IEEE Trans. Magn. 37, 1649 (2001).

[19] S. Hosaka, T. Shintani, M. Miyamoto, A. Hiritsune, M. Terao, M. Yoshida, S. Honma, and S. Kammer, J. Appl. Phys. 79, 8082 (1996).

[20] S. Hosaka. M. Ishihashi, H. Hayakawa, S. Hishi, and M. Migikata, Jpn. J. Appl. Phys. (Part 1), 21, 543 (1984).

[21] S. Ogata, M. Tada, and M. Yoneda, Appl. Opt. 33, 2032 (1994).

[22] Y. Kojima, H. Kitahara, M. Katsumura, and Y. Wada, Jpn. J. Appl. Phys. (Part 1), 37, 2137 (1998).

[23] S. Hosaka, H. Sano, M. Shirai, and H. Sone, Appl. Phys. Lett. 89, 223131 (2006).

[24] S. Hosaka, Z. Mohamad, M. Shirai, H. Sano, Y. Yin, A. Miyachi, H. Sone, Microelectronic Eng. 85, 774 (2008).

[25] S. Hosaka, H. Hayakawa, M. Ichihashi, K. Asanami, S. Nishi, and M. Migitaka, Proc. Microcircuits Eng. (Achen, 1979) p. 7.

[26] J. K. W. Yang, B. Cord, H. Duan, K. K. Berggren, J. Klingfus, S. Nam, K. Kim, M. Rooks, J. Vac. Sci. Technol. B27, 2622 (2009). 


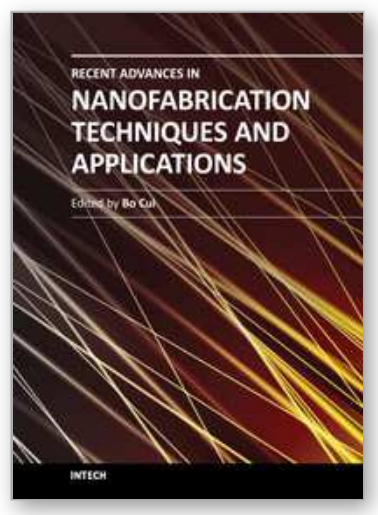

\author{
Recent Advances in Nanofabrication Techniques and Applications \\ Edited by Prof. Bo Cui
}

ISBN 978-953-307-602-7

Hard cover, 614 pages

Publisher InTech

Published online 02, December, 2011

Published in print edition December, 2011

Nanotechnology has experienced a rapid growth in the past decade, largely owing to the rapid advances in nanofabrication techniques employed to fabricate nano-devices. Nanofabrication can be divided into two categories: "bottom up" approach using chemical synthesis or self assembly, and "top down" approach using nanolithography, thin film deposition and etching techniques. Both topics are covered, though with a focus on the second category. This book contains twenty nine chapters and aims to provide the fundamentals and recent advances of nanofabrication techniques, as well as its device applications. Most chapters focus on indepth studies of a particular research field, and are thus targeted for researchers, though some chapters focus on the basics of lithographic techniques accessible for upper year undergraduate students. Divided into five parts, this book covers electron beam, focused ion beam, nanoimprint, deep and extreme UV, X-ray, scanning probe, interference, two-photon, and nanosphere lithography.

\title{
How to reference
}

In order to correctly reference this scholarly work, feel free to copy and paste the following:

Sumio Hosaka (2011). Electron Beam Lithography for Fine Dot Arrays with Nanometer-Sized Dot and Pitch, Recent Advances in Nanofabrication Techniques and Applications, Prof. Bo Cui (Ed.), ISBN: 978-953-307-6027, InTech, Available from: http://www.intechopen.com/books/recent-advances-in-nanofabrication-techniquesand-applications/electron-beam-lithography-for-fine-dot-arrays-with-nanometer-sized-dot-and-pitch

\section{INTECH}

open science | open minds

\section{InTech Europe}

University Campus STeP Ri

Slavka Krautzeka 83/A

51000 Rijeka, Croatia

Phone: +385 (51) 770447

Fax: +385 (51) 686166

www.intechopen.com

\section{InTech China}

Unit 405, Office Block, Hotel Equatorial Shanghai

No.65, Yan An Road (West), Shanghai, 200040, China

中国上海市延安西路65号上海国际贵都大饭店办公楼 405 单元

Phone: +86-21-62489820

Fax: $+86-21-62489821$ 
(C) 2011 The Author(s). Licensee IntechOpen. This is an open access article distributed under the terms of the Creative Commons Attribution 3.0 License, which permits unrestricted use, distribution, and reproduction in any medium, provided the original work is properly cited. 